number of tables and the rates of interest what they may. The rule, in Wallace's words, is as follows:-

"Let A, B, C, D be the values of an annuity on a given life at 3,4 , 5,6 per cent.; and $A^{\prime}, B^{\prime}, C^{\prime}, D^{\prime}$ the values on a life three years older. Find the values of $a^{\prime \prime}$ and $b^{\prime \prime}$, also $\alpha^{\prime \prime}$ and $\beta^{\prime \prime}$, from these formules.

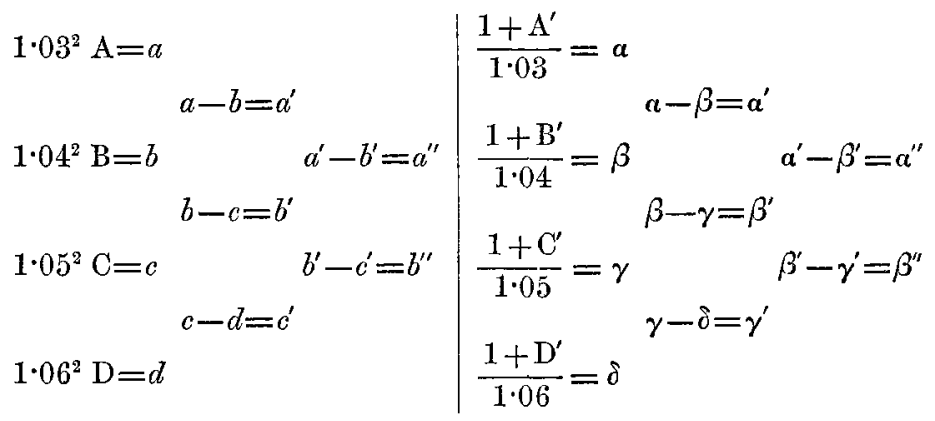

'Then, if the calculations have been rightly performed,

$$
\frac{a^{\prime \prime}}{b^{\prime \prime}}=\frac{\boldsymbol{\alpha}^{\prime \prime}}{\beta^{\prime \prime}}
$$

If ouly two tables were employed, the rule would be as follows:-

Let $A$ and $B$ be the annuities at a given age, $A^{\prime}$ and $B^{\prime}$ those at one year older, $v$ and $w$ the present values of $£ 1$ due in one year. Then

$$
\frac{\mathrm{A}\left(1+\mathrm{B}^{\prime}\right)}{\mathrm{B}\left(1+\mathrm{A}^{\prime}\right)}=\frac{v}{w} \text {. }
$$

I am not aware that these rules have been given. In the event of their having occurred to some one else, I may state that Wallace communicated them to Mr. Galloway, and thereby secured his right, in October, 1834, as appears by a memorandum.

\title{
University College, London,
} I remain, dear Sir, yours faithfully, May 10, 1852.

A. DE MORGAN.

\section{ON A METHOD OF OBTAINING FROM A TABLE OF ASSUMED "WHOLE LIFE" PREMIUMS THE CORRESPONDING \\ TABLE OF MORTALITY.}

\section{To the Editors of the Assurance Magazine.}

GentLemen,-Before proceeding further, it may be well to explain the object which the method about to be described has in view.

In the present day, when so many new classes of risks are undertaken, even by offices of the highest standing, it will often be of importance to be able to determine the "short period," or "definite payments," \&c. premium, which fairly corresponds to an assumed "whole life" premium. The cases of " hazardons" risks, and of extras for "foreign residence," are instances in point, as well as all the various classes of assurances involving 
deteriorated lives. Of course, the present notes will be nseless if the theory be maintained that the extra charge merely covers the extra risk, and so should apply with equal force as well to a "short period" as to a "whole life" assurance. But this, it is submitted, must be in many instances an erroneous hypothesis, and it is to endeavour to meet the want which may be felt by those who hold a different opinion that the following method was investigated. It need only be added, that it was that followed in an actual case in practice.

Suppose, then, that we have a table of "whole life" premiums, formed no matter how, and that these are reduced, by throwing off such per centages as may be thought necessary, to pure premiums.

The first step will be to obtain the corresponding annuities; and this is done by the well known relation-

$$
\varpi_{x}=\frac{1}{1+a_{x}}-(1-v) ;
$$

whence

$$
\frac{1}{1+a_{x}}=\pi_{x}+1-v
$$

and hence

$$
\lambda\left(1+a_{x}\right)=\kappa \cdot \lambda \cdot\left(\varpi_{x}+1-v\right) .
$$

From $\lambda\left(1+a_{x}\right)$ we obtain at once $1+a_{x}$, and also $\lambda a_{x}$, the latter by Gray's 'Tables; and thus there is so far a check on the latter part of the work, as the corresponding values of $a_{x}$ will (if the operation has been rightly done) be less by unity than those of $1+a_{x}$. The reason for finding both $\lambda\left(1+a_{x}\right)$ and $\lambda a_{x}$ will appear in the sequel.

And here it may be observed, that for practical purposes it will be sufficient to commence several years after age 0 , say at age 12 or 15 , and that the annuities at the oldest ages are not proposed to be found in the way just explained, but that it is suggested that we should suppose the lives to exhaust themselves at some advanced age, such as the nature of the case in other respects seems to render appropriate; and-having obtained the actual annuity at some younger age (where the tabular rates terminate), to interpolate the intervening values in such a way as may be deemed best. The common method of equal differences will probably in most cases be sufficient.

Having thus obtained the annuities, the remaining process will be as follows:-

We know that

$$
a_{x-1}=\left(1+a_{x}\right) \frac{l_{x}}{l_{x-1}} v
$$

whence

$$
\frac{l_{x-1}}{l_{x}}=\frac{1+a_{x}}{a_{x-1}} v ;
$$

consequently

$$
\lambda l_{x-1}=\lambda l_{x}+\lambda\left(1+a_{x}\right)+\kappa \lambda a_{x-1}+\lambda v
$$

from which equation the number alive at any particular age being given, that at the next younger age may be found by the addition of logarithmic 
values already known; and assuming that but one is left alive at the extreme age (whatever that may be fixed upon to be), the number alive at all the younger ages may be found. The $\mathrm{D}$ and $\mathrm{N}$ columns may then be found in the usual way, except that it will be found desirable to carry on the calculation of the $l_{x}, \mathrm{D}_{x}$, and $\mathrm{N}_{x}$ at once, so that any error (not unlikely to arise in so many successive dependent operations) may be at once detected.

In conclusion, the only source of accumulative error may be pointed out, viz., that arising from the value of $v$ being not exact. This may be found in extent, and corrected by a periodic alteration in the last figure; and for those who may employ 3 per cent. as the basis of their calculations, it may be mentioned that an error in excess will occur in each of the operations involving $v$, the process being, of course, a dependent one.

Your obedient servant,

\section{Scottish Widows' Fund Assurance Society, Edinburgh, May 12, 1852.}

WILLIAM WYLIE.

\section{ON DE WIT'S HYPOTHESIS AS TO THE RATE OF MORTALITY.}

\section{To the Editors of the Assurance Magazine.}

Gentlemen, - All who study the science of life contingencies, and especially those who take an interest in the history of its rise and progress, are under great obligations to Mr. Hendriks for his notices in the Assurance Magazine regarding two remarkable works new to the English reader - that of Tetens, who had anticipated Barrett in his method of simplifying assurance calculations, and who was also in possession of more powerful methods of practical computation than any known in this country until the last few years; and, more recently, the restoration of the earliest treatise on life annuities, by John De Wit, which, although printed, had from the time of its publication eluded the search of all previous inquirers.

The earliest English writing upon the subject of life annuities is the paper by Dr. Halley in the Philosophical Transactions for 1693. The date of De Wit's treatise is 1671 , but from its suppression Halley could not have seen or obtained any information from it, so that his paper is as original as if De Wit had not written. Halley there gave the first Life Table ever constructed upon true principles from real observations, and his knowledge of the properties of life tables, and the mode of applying them to the computation of life annuities on one or more lives, was as perfect as ours is at the present day. The actual computation of life annuity tables was, however, much facilitated by deducing the value of an annuity upon age $x$ from that on age $x+1$, the rule for which was given by De Moivre.

Such is the nature of Halley's paper; and now, having De Wit's treatise restored to us through Mr. Hendrik's perseverance and labour, it will be interesting to examine if it is of the same order of merit, and if its publication in England would have destroyed the originality of Halley's paper. I have examined it with this view, and have come to the conclusion that De Wit's treatise is so vitiated by fundamental errors, that it does not contain the true method of calculating life annuities, and that its repntation could not at any time have long survived its perfect publication. 